\title{
Mediating effects of parents' coping strategies on the relationship between parents' emotional intelligence and sideline verbal behaviors in youth soccer
}

Pedro Teques

Luis Calmeiro

Henrique Martins

Daniel Duarte

Nicholas L. Holt

Accepted author manuscript version reprinted, by permission, from Journal of Sport and Exercise Psychology, 2018, https://doi.org/10.1123/jsep.2017-0318 (C) Human Kinetics, Inc. 


\section{Mediating Effects of Parents' Coping Strategies on the Relationship Between Parents'} Emotional Intelligence and Sideline Verbal Behaviors in Youth Soccer

6

Correspondence concerning this article should be addressed to Pedro Teques, Instituto

Politécnico da Maia, Av. Carlos de Oliveira Campos, 4475-690 Maia, Porto, Portugal.

E-mail: pteques@ipmaia.pt

Telephone: $(+351) 229866026$ 


\section{Abstract}

The overall purpose of this study was to examine the mediating effects of parents' coping strategies on the relationship between parents' emotional intelligence (EI) and sideline verbal behaviors during their children's soccer games. Participants were 232 parents (120 mothers, 110 fathers) of youth soccer players aged 9 to 13 years old. Observations in situ were carried on 30 soccer games during a soccer tournament. At the end of the game, parents were approached and asked to complete the Emotional Intelligence Scale and the Brief COPE scale. SEM analyses revealed that adaptive and maladaptive coping mediated the relationship between regulation of emotion and parents' praise/encouragement, and negative and derogatory comments during the game. In addition, game result moderated the relationships between EI, coping strategies and parents' behaviors. Emotional regulation and adaptive coping may promote desirable parents' sideline behaviors and reduce undesirable behaviors. Keywords: adaptive coping, emotional regulation, encouragement, maladaptive coping, praise, soccer. 
Mediating Effects of Parents' Coping Strategies on the Relationship Between Parents' Emotional Intelligence and Sideline Verbal Behaviors in Youth Soccer

Parents exert a powerful influence on their children's sporting experiences via the emotional climate they create. This emotional climate can be conveyed in numerous settings, including the family home (Holt, Tamminen, Black, Mandigo, \& Fox, 2009), during car rides (Tamminen, Poucher, \& Povilaitis, 2017), at tournaments (Knight \& Holt, 2013a) and on the sidelines while parents are spectators (Holt, Tamminen, Black, Sehn, \& Wall, 2008). Parents' sideline verbal behaviors have received considerable attention in the youth sport literature.

Researchers have shown that parents engage in a wide range of sideline behaviors, and whereas the majority of comments made by parents during games are positive and directed toward athletes, negative behaviors do occur (Bowker et al., 2007; Holt et al., 2008; Kidman, McKenzie, \& McKenzie, 1999). Nonetheless, coaches and sport administrators have reported concerns with negative parental sideline verbal behaviors, including parents verbally abusing officials and other parents, undermining coaches, calling out their children's weaknesses, and providing conditional support based on children's performances (Ross, Mallett, \& Parkes, 2015).

Several factors appear to influence the nature and content of parents' verbal comments on the sidelines. For example, Holt et al. (2008) suggested a model which emphasizes the role of parents' empathy towards their children, the emotional intensity of the games and parents' knowledge and expertise of the sport. Other researchers suggested that constructs such as parents' anger (Omli \& LaVoi, 2012), goals relevant to interpersonal communication (Dorsch, Smith, Wilson, \& McDonough, 2014), and control-orientation (Goldstein \& Iso-Ahola, 2008) also influence sideline behavior. For instance, Goldstein and Iso-Ahola (2008) found that parents with high control-orientation exhibited more ego defensiveness and reported higher levels of anger and aggressive spectator behavior than parents with low control-orientation. 
Also, parents may encounter a range of organizational and developmental stressors in relation to their children's participation in youth sport, and must be able to cope with the emotional demands of competition (Harwood \& Knight, 2009). Thus, given that parents (a) create the emotional climate that supports (or detracts from) their children's sporting experiences, (b) experience a variety of emotional, and (c) have the need to monitor others' and their own emotions, it is plausible that emotional intelligence (EI), will enable parents to cope with their children's competitive situations and behave in appropriate ways. Indeed, Harwood and Knight (2015) recently suggested that EI ability is a component of sport parenting expertise. However, relationships between parent EI, coping, and verbal sideline behaviors have yet to be examined in the youth sport literature.

Salovey and Mayer (1990) originally defined EI as a "subset of social intelligence that involves the ability to monitor one's own and others' feelings and emotions, to discriminate among them and to use this information to guide one's thinking and actions" (p. 189). In addition to this 'ability perspective', EI has also been conceptualized as a trait (Petrides, Pita, \& Kokkinaki, 2007). In an attempt to reconcile these different perspectives, Mikolajczak (2009) proposed a tripartite model, in which EI is organized in three levels. The first level consists of knowledge about emotions (e.g., parents' knowledge about strategies to regulate emotions). The second level refers to the ability to use specific emotion regulation strategies. This component reflects the ability perspective (Salovey \& Mayer, 1990) and involves a set of hierarchical specialized skills, such as the ability to perceive emotions, understand emotions, manage them, and use them to facilitate thinking. The third level refers to the disposition (trait) to behave in a certain way in emotional situations. This component belongs to the domain of personality and affect, such as stress tolerance, adaptability, or social competence to deal with the emotional situation (e.g., Petrides et al., 2007). 
Measures of EI reflect the theoretical approach researchers follow in sport (Laborde, Dosseville, \& Allen, 2016). The most frequent trait measure is the 153-item Trait Emotional Intelligence Questionnaire (TEIQue), which has demonstrated sound psychometric characteristics within a sample of athletes of various sports (Laborde, Dosseville, Guillen, \& Chavez, 2014). This measure has been shown to be preferable to Schutte EI scale (Schutte et al., 1998) and the Bar-On Emotional Quotient Inventory (Bar-On, 2004) as studies in sport have not been able to replicate the hypothesized factor structure (Laborde et al., 2014; Laborde et al., 2016). Concerning measurement of EI as an ability, the Mayer-Salovey-Caruso Emotional Intelligence Test (MSCEIT) is a EI performance test that measures the subcomponents of Salovey and Mayer's (1990) framework: perception, use, understanding and management of emotion. Using MSCEIT, Dunn, Brackett, Ashton-James, Schneiderman, and Salovey (2007) showed that spectators of a basketball game who are high in EI ability made more accurate forecasts about their own affective responses to the outcome of the event. Despite its clear theoretical foundation of MSCEIT, Laborde et al. (2016) summarize the limitations of this instrument including its complex scoring system, overlap with other personality and intelligence dimensions, and lack of validation studies in sport. In addition, its 141-items renders it impractical for field studies. Another measure of EI as an ability based on Salovey and Mayer's (1990) framework is the 16-item Wong and Law EI Scale (WLEIS; Wong \& Law, 2002). Lee and Chelladurai (2016) used the WLEIS within a sample of coaches and revealed good psychometric characteristics in sport. In the current study, we considered the ability perspective using the WLEIS because we aim at specifying the constructs pertaining to parents' recognition of emotions in the self and others, to regulate their behaviors and to use this information to facilitate their actions during their child's soccer games, in line with Salovey and Mayer's (1990) framework. 
According to MacCann, Fogarty, Zeidner, and Roberts (2011), EI leads to more adaptive coping, which in turn leads to better behavioral outcomes. In the earliest conceptualizations of EI, Salovey et al. (1999) suggested promising links between EI and coping with stressful events, and proposed the Emotional Coping Hierarchy model. This model has three sequential levels: the first level relates to the basic emotional skills of emotional appraisal; the second level represents a more complex component of emotional knowledge, such as emotional use and understanding; finally, the third level addresses emotional regulation as the key dimension of EI that facilitates the coping process. Joseph and Newman (2010) empirically confirmed the relationships between these levels via metaanalytic data. These authors postulated a progressive pattern among EI levels, in which emotion perception causally precedes emotion use and understanding, which in turn precedes emotion regulation and behavior. Emotion regulation is associated with individuals' adaption to a specific encounter because it implies the management of emotions in a flexible manner that is consistent with their goals (Salovey et al., 1999). In sport, researchers have only recently started to explore the relationships between EI and coping strategies. For example, Laborde, You, Dosseville, and Salinas (2012) reported that athletes with higher EI scores engaged in more adaptive coping, such as task-oriented coping strategies (e.g., appraise competition as a challenge), whereas lower EI scores were related to disengagement-oriented coping (e.g., behavioral avoidance and venting of unpleasant emotions).

The overall purpose of this study was to examine the mediating effects of coping strategies between EI and parents' sideline verbal behaviors during their children's soccer games. We followed Salovey et al.'s (1999) Emotional Coping Hierarchy model (Figure 1), assuming that the emotions' appraisal, use of emotion, and regulation of emotion are related to parents' behaviors in a sequential mode. Thus, we predicted that regulation of emotion is the primary determinant of parents' behaviors, and it will be positively related with desirable 
parents' sideline verbal behaviors (i.e., praise/encouragement) and negatively with undesirable parents' sideline verbal behaviors (i.e., performance-contingent feedback, instruction, striking a balance, negative comments, and derogatory comments) during their children's soccer games (Hypothesis 1). Furthermore, we hypothesized that: regulation of emotion will be positively related with adaptive coping and negatively with maladaptive coping strategies (Hypothesis 2); adaptive coping will positively mediate the relationships between regulation of emotion and desirable parents' sideline verbal behaviors (Hypothesis 3), and negatively mediate the relationship with undesirable parents' verbal behaviors (Hypothesis 4); maladaptive coping will positively mediate the relationships between regulation of emotion and undesirable parents' sideline verbal behaviors (Hypothesis 5), and positively mediate the relationship with undesirable parents' verbal behaviors (Hypothesis 6). Finally, following suggestions of gender differences in the EI (Farrelly \& Austin, 2007) and in the use of coping strategies (Matud, 2004), and that situational conditions may influence parents' sideline behaviors (Holt et al., 2008), we were also interested in how parents' gender (Hypothesis 7) and game outcome (Hypothesis, 8) moderate the relationships estimated in the hypothesized model.

\section{[FIGURE 1]}

\section{Methods}

\section{Participants}

During an international youth soccer tournament, 232 parents (120 mothers, 110 fathers; 2 participants did not identify gender) of youth soccer players (boys and girls who were between 9 and 13 years of age) participated in both phases of this study. Parents' age ranged from 28 to 62 years old $(M=40.50, S D=5.63)$. Twenty-four-point six per cent of the parents had completed lower secondary education, $33.5 \%$ upper secondary education, $38.1 \%$ had an undergraduate degree and $3.8 \%$ a master degree. 


\section{Design and procedure}

Observations. Ethical approval was obtained from the faculty ethics committee and the board of directors for the IBERCUP - International Youth Football Tournament. The

IBERCUP is one of the largest youth football tournaments in the world, a weeklong event that involves more than 200 teams and 2500 young athletes from several different countries.

Naturalistic observations were carried out in 30 soccer games during the week of the tournament (60 soccer teams involved), which permitted the observation of various situations (e.g., first-round games, semi-finals, final games). The length of the games was 40 minutes. We observed games in two age groups, Under-11 and Under-13, with mixed-gender participation. The number of parents of girls in this sample is small $(n=12)$.

Observer training. Prior to conducting the observations, four observers (three lecturers with $\mathrm{PhD}$ in Sport and Exercise Psychology and a teacher of physical education with a master degree in Sports Coaching) were trained following the guidelines of McKenzie and van der Mars (2015). Training comprised the following phases: identification of the categories of the system (i.e., definition of behavioral categories); discussion of the observation protocol (i.e., interactive discussion about behavioral scenarios); evaluation of the learning of the categories (i.e., interpretation of video segments created by the first author); and practice and application of the observation system in situ. The observation system was tested in three under-12 soccer games. After the first game of observation training, we decided to implement a maximum ratio of four parents to one observer, depending on the conditions of the crowd (e.g., parents very close together, presence of flags, the sound of trumpets). Thus, the four observers were divided into two teams. Each team randomly chose four parents to observe at each game, coding in three games a total of 164 verbal behaviors using a paper-and-pencil observation system (see Supplementary Material: Parents' observation system). For each of the observed categories, we found acceptable Cohen's kappa coefficients ranged between 0.86 and 0.91 , by 
comparing two independent observations related to the same match (McKenzie \& van der Mars, 2015).

Participant recruitment. During the tournament, the observers wore the same clothing as the tournament staff and volunteers. At the beginning of each game, observers randomly chose four parents to observe. At the end of the game, parents were approached, informed about the purpose of the study and that they had been observed, and invited to participate in the remainder of the study (i.e., the completion of the questionnaires). A total of $96.6 \%$ of parents observed agreed to participate in the remaining of the study and provided informed consent. Those parents who did not agree, did not have their children playing in the game observed, or were not parents (e.g., grandparents or other relatives) were excluded from the study and their observational data were not used. Only data from the 232 parents who participated in both stages of this research (i.e., they were observed and completed the questionnaires) were included in the analysis.

Parents who agreed to participate were directed to a classroom-type setting. Prior to the administration of the questionnaires, it was made clear that participation in this study was voluntary and that all responses would be confidential. A research assistant answered any questions during the data collection. Participants took about 10 minutes to complete the questionnaires and immediately returned them to a research assistant.

\section{Measures}

Emotional intelligence. The Portuguese version (Rodrigues, Rebelo, \& Coelho, 2011) of the Wong and Law Emotional Intelligence Scale (WLEIS; Wong \& Law, 2002) was used to assess parents' perceptions of their EI abilities. Following Lee and Chelladurai (2016), we used the WLEIS because (a) it is representative of the original EI construct defined by Salovey and Mayer (1990), (b) it is short, (c) there is evidence of good psychometric 
characteristics, both for its English (e.g., Libbrecht, De Beuckelaer, Lievens, \& Rockstuhl, 2014) and Portuguese versions (Carvalho, Guerrero, Chambel, \& González-Rico, 2016).

WLEIS is a short 16-item self-report scale that was validated in different countries, showing psychometrically sound characteristics, such as construct and criterion validity, reliability, and measurement invariance (e.g., Libbrecht et al. 2014). Recently, the Portuguese version of WLEIS has demonstrated consistent psychometric characteristics via confirmatory factor analysis, reproducing the original factor structure (Carvalho et al., 2016). WLEIS is based on the revised four-dimensional EI model originally theorized by Salovey and Mayer (1990). In this model, EI consists in four dimensions: self-emotions appraisal (e.g., "I really understand what I feel”), other's emotions appraisal (e.g., "I have good understanding of the emotions of people around me"), use of emotion (e.g., "I would always encourage myself to try my best"), and emotion regulation (e.g., "I can always calm down quickly when I am very angry”). All items were responded on 7-point Likert-type scale ranging from $1=$ totally disagree to $7=$ totally agree. Cronbach alpha coefficients for the current study were 0.79 (use of emotion), 0.81 (self-emotions appraisal), 0.84 (regulation of emotion), and 0.86 (other's emotions appraisal).

Coping strategies. The Portuguese version (Ribeiro \& Rodrigues, 2004) of the Brief COPE (Carver, 1997), a 28-item self-report questionnaire, was used to assess coping. We focused on situational coping, which refers to coping with a specific event at a precise moment in time (Lazarus, 1991). Participants were asked to indicate what they did to cope during the soccer game in which their children competed. According to Carver (1997), two broad coping dimensions integrate the 14 subscales: adaptive coping strategies (i.e., active coping, acceptance, humor, religion, planning, positive reframing, and using instrumental and emotional support) and maladaptive coping strategies (i.e., behavioral disengagement, denial, self-blame, self-distraction, substance use, and venting negative emotion). Items were 
answered on a 4-point Likert-type scale, ranging from $1=I$ have not used this at all to $4=I$ have used it a lot. In this study, both adaptive (.83) and maladaptive coping strategies (.79) had adequate Cronbach alpha coefficients.

Parents' sideline verbal behaviors. We used Holt et al.'s (2008) observational system to examine parents' sideline behaviors in competitive sport settings (e.g., Dorsch et al., 2014). Holt et al. (2008) identified six categories of parents' verbal reactions to children's performance behaviors (see Supplementary Material: Parents' observation system): (a) praise/encouragement denotes more supportive comments (e.g., "Very well, John!" "Let's go, team!”); (b) performance-contingent feedback refers to comments intended to improve children's performance (e.g., "Now it's time to attack, boys"); (c) instruction refers to direct commands (e.g., "Pass the ball!"); (d) striking a balance refers to verbal reactions that are intended to provide an equilibrium between positive and negative comments (e.g., "Oh, no John... That's okay, good try!'); (e) negative comments refers to general negative reactions during the game (e.g., "Bad decision, John!"); and (f) derogatory comments refers to depreciating and potentially harmful reactions (e.g., "Hey, ref, go home!" “That's embarrassing, John!"). Similar to Holt and colleagues (2008), we also recorded the intended target of each comment: athletes, coaches and referees.

\section{Data analysis}

The two-step approach to maximum likelihood structural modeling was implemented using AMOS 23. First, the measurement model was estimated by conducting a confirmatory factor analysis (CFA) to evaluate the extent to which each of the variables were adjusted to its indicators. Subsequently, the structural model estimation was performed to test the research hypotheses. The adequacy of the models was assessed through a variety of fit indices. We followed the cut off values (CFI and TLI $>.95$, RMSEA $<.06$, and SRMR $<.08$ ) suggested by $\mathrm{Hu}$ and Bentler (1999) as excellent model fit; however, Marsh, Hau, and Wen (2004) have 
contended that the rigorous approach of $\mathrm{Hu}$ and Bentler (1999) to the cut of values could lead to an incorrect rejection of an appropriate model. Thus, we considered the cut off values (CFI and TLI > .90, RMSEA and SRMR < .08) proposed by Hair, Black, Babin, and Anderson (2014) as adequate model fit.

Mediation analysis. With mediation analysis we explored the direct and indirect effects of the variables in this study on the outcome variable. Specifically, EI variables were conceptualized to have an indirect association with parents' sideline verbal behaviors and coping strategies were conceptualized as mediators. The significance of the direct and indirect effects was assessed using the bootstrap resampling procedure (1000 bootstrap samples), via bias corrected $95 \%$ confidence intervals $(\mathrm{CI})$. An indirect effect is considered significant (at $\leq$ 0.05 ) if its $95 \%$ CI does not include zero (Williams \& MacKinnon, 2008). Effect size values of $0.1,0.3$, and 0.5 were considered small, medium and large, respectively (Cohen, 1988).

Moderation analysis. We were also interested to know possible changes on the relationships between the variables in the study as a function of the moderating influence of gender and game outcome. Thus, two multi-group analyses were conducted to discern the extent to which the parents' gender and game outcome moderate the path coefficients estimated in hypothesized model. Differences between models were accessed with chi-square $\left(\chi^{2}\right)$ tests of significance and CFI difference ( $\triangle \mathrm{CFI}$ ) values (Cheung \& Rensvold, 2002).

Between groups differences was further assessed by sequentially examining the unconstrained and the constrained structural paths. The significance of the structural paths was assessed using critical ratio for differences produced by AMOS (significance $\geq 1.96$ ).

\section{Results}

A priori power analysis to compute required sample size was conducted using GPower 3.1. (Faul, Erdfelder, Buchner, \& Lang, 2009) considering the following input parameters: effect size $\mathrm{f}^{2}=0.1$; alpha $=0.05$; statistical power $=0.95$; and 6 predictors. The required 
sample was 215. A preliminary inspection to the data revealed that missing values comprised $0.2 \%$ of cells in the original data, without any missing data patterns. Consequently, missing data were imputed using AMOS's regression procedure. Mardia's coefficient (58.12) exceeded the expected values for the multivariate normality. Hence, a Bollen-Stine bootstrap (B-S) was used for subsequent analysis (Nevitt \& Hancock, 2001). In addition, variance inflation factors (VIF) were assessed to verify collinearity within all study variables, with values ranging from 1.23 (self-emotions appraisal) to 1.76 (adaptive coping), showing acceptable conditions to conduct regression analysis (VIF < 10; Hair et al., 2014).

\section{Measurement model}

Table 1 shows means, standard deviations, and bivariate correlations among all variables. Parents revealed high self-emotions appraisal $(M=3.96, S D=0.69)$ and low levels of maladaptive coping $(M=2.22, S D=0.50)$. Regarding sideline verbal behaviors, parents expressed a mean of $32.80(S D=12.60)$ comments per game (984 parents' verbal behaviors were recorded). Most of the verbalized behaviors were praise/encouragement $(M=16.60, S D$ $=6.30$ ), followed by performance-related behaviors (i.e., performance-contingent feedback and instruction), negative and derogatory comments. Negative and derogatory comments were rare (4\%), and mainly targeted to the referee. Parents' comments were directed to athletes $(92 \%)$, referees $(6 \%)$ and coaches $(2 \%)$.

The correlation matrix showed a variety of associations between variables (Table 1). In general, all EI variables correlated between each other, while regulation of emotion was related with both adaptive $(r=.17, p<0.01)$ and maladaptive $(r=.33, p<0.01)$ coping strategies. In turn, adaptive coping strategies correlated positively with praise/encouragement $(r=.38, p<0.01)$ and negatively with negative $(r=-.16, p<0.05)$ and derogatory $(r=-.11, p$ $<0.05)$ comments. Maladaptive coping correlated negatively with praise/encouragement $(r=$ 
$-.12, p<0.05)$ and positively with striking a balance $(r=.23, p<0.01)$, and negative $(r=.18$, $p<0.01)$ and derogatory $(r=.21, p<0.01)$ comments.

The test of the measurement model included parents' own and other's emotions appraisal, use of emotion, regulation of emotion, and adaptive and maladaptive coping as latent variables. Results suggest an excellent fit to the data $\left[\chi^{2} / d f=475.32(390), p<.001\right.$, $\mathrm{TLI}=0.95, \mathrm{CFI}=0.95, \mathrm{SRMR}=0.02, \mathrm{RMSEA}=0.04(\mathrm{CI}=0.04,0.05)]$.

\section{[TABLE 1]}

\section{Structural model}

The assessment to the hypothesized mediational model displayed an inadequate fit to the data $\left[\chi^{2} / d f=906.53(577), p<.001, \mathrm{TLI}=0.88, \mathrm{CFI}=0.89, \mathrm{SRMR}=0.05, \mathrm{RMSEA}=\right.$ $0.06(\mathrm{CI}=0.06,0.07)]$. Some of the criteria demonstrated excellent fit $(\mathrm{SRMR}<.08$ and RMSEA < .06). However, the incremental indices showed inadequate fit (CFI and TLI > .90). In this situation, the generation of an alternative model should be considered, provided it has theoretical support, it is parsimonious, and it fits the data (Kline, 2011). Further analysis indicated no associations from regulation of emotion, adaptive and maladaptive coping to performance-contingent feedback $(\beta=0.03, p>0.05 ; \beta=-0.02, p>0.05$, and $\beta=0.04, p>$ 0.05 , respectively) or from regulation of emotion, adaptive and maladaptive coping to instruction $(\beta=-0.04, p>0.05 ; \beta=0.01, p>0.05$, and $\beta=0.06, p>0.05$, respectively). Thus, these variables were excluded from the revised path model, and no additional modifications were applied. Consequently, the revised model showed an adequate fit to the data $[\chi 2 / \mathrm{df}=$ $603.46(514), \mathrm{p}<.001, \mathrm{TLI}=0.90, \mathrm{CFI}=0.91, \mathrm{SRMR}=0.04, \mathrm{RMSEA}=0.06(\mathrm{CI}=0.05$, $0.06)]$.

The standardized direct effects for the revised model are presented in Figure 2. As expected, the EI variables were related in a sequential mode. Further, regulation of emotion showed positive significant relationships on praise/encouragement $(\beta=0.35, p<0.01)$, and 
adaptive coping $(\beta=0.19, p<0.05)$, whereas negative associations were found with maladaptive coping $(\beta=-0.32, p<0.01)$, and negative $(\beta=-0.18, p<0.05)$ and derogatory comments $(\beta=-0.16, p<0.05)$. Adaptive coping was positively associated with praise/encouragement $(\beta=0.31, p<0.01)$, and negatively associated with negative comments $(\beta=-0.15, p<0.05)$. Moreover, maladaptive coping was related with striking a balance $(\beta=$ $0.22, p<0.01)$, negative comments $(\beta=0.21, p<0.01)$ and derogatory comments $(\beta=0.28, p$ $<0.01)$. Non-significant relationships were identified between regulation of emotion to striking a balance $(\beta=0.01, p>0.05)$, adaptive coping to striking a balance $(\beta=0.06, p>$ $0.05)$ and derogatory comments $(\beta=-0.02, p>0.05)$, and maladaptive coping to praise/encouragement $(\beta=-0.01, p>0.05)$.

[FIGURE 2]

Findings of the mediation analysis between EI, coping strategies and parents' sideline verbal behaviors are displayed in Table 2. Regulation of emotion showed significant indirect effects on praise/encouragement and negative comments via adaptive coping $(\beta=.18 ; \mathrm{CI}=$ $.10, .29 ; \beta=-.09 ; \mathrm{CI}=-.21,-.02 ;$ respectively). Moreover, regulation of emotion had significant indirect effects on negative comments $(\beta=-.12 ; \mathrm{CI}=-.25,-.02)$ and derogatory comments $(\beta=-.08 ; \mathrm{CI}=-.19,-.01)$ via maladaptive coping strategies.

\section{[TABLE 2]}

\section{Moderating effects of gender and game result}

We performed two multi-group confirmatory factor analyses to detect whether the path coefficients differed significantly between mothers and fathers, and between wins and losses. With regard to gender, the fit of both unconstrained $[\chi 2 / d f=1101.33(1154), p<.001, \mathrm{TLI}=$ $0.90, \mathrm{CFI}=0.91, \mathrm{SRMR}=0.04, \mathrm{RMSEA}=0.05(\mathrm{CI}=0.04,0.05)]$ and constrained structural paths $[\chi 2 / d f=1123.89(1195), p<.001, \mathrm{TLI}=0.90, \mathrm{CFI}=0.91, \mathrm{SRMR}=0.05, \mathrm{RMSEA}=$ $0.06(\mathrm{CI}=0.05,0.06)]$ models was acceptable. The $\chi 2$ statistic indicated that these models 
were invariant $[\Delta \chi 2(41)=22.56, p>0.05]$, while the critical ratios for differences between structural paths revealed that two hypothesized relationships differed significantly between groups. The paths from use of emotion to regulation of emotion $(Z=2.22, p<0.05)$, and from regulation of emotion to praise/encouragement $(Z=2.09, p<0.05)$, evidenced significant differences. Both paths coefficients for mothers $(\beta=0.72, p<0.01 ; \beta=0.42, p<0.01$, respectively) were greater than the coefficients for fathers $(\beta=0.28, p<0.01 ; \beta=0.19, p<$ 0.05 , respectively). These findings suggest that mothers with high use of emotion scores were more likely to better regulate their emotions than fathers. In turn, mothers with high regulation of emotion were more likely to praise and encourage during their child's games than fathers.

The same procedure was performed to examine differences on paths coefficients for parents who watched games when their children won compared to when their children lost. The unconstrained $[\chi 2 / d f=1553.16(1154), p<.001, \mathrm{TLI}=0.88, \mathrm{CFI}=0.89, \mathrm{SRMR}=0.06$, $\mathrm{RMSEA}=0.07(\mathrm{CI}=0.06,0.07)]$ and constrained structural paths $[\chi 2 / d f=766.22(1195), p<$ $.001, \mathrm{TLI}=0.91, \mathrm{CFI}=0.92, \mathrm{SRMR}=0.04, \mathrm{RMSEA}=0.05(\mathrm{CI}=0.04,0.05)]$ models revealed satisfactory fit. The $\chi^{2}$ statistic indicated that these models were significantly different $[\Delta \chi 2(41)=786.94, p<0.001]$. The critical ratio for differences indicated that maladaptive coping revealed a significantly different relationship on negative $(Z=3.13, p<$ $0.05)$ and derogatory $(Z=3.55, p<0.05)$ comments. The magnitude of the paths from maladaptive coping to negative and derogatory comments was greater for losses $(\beta=0.32, p<$ $0.01 ; \beta=0.37, p<0.01$, respectively) than for wins $(\beta=0.03, p>0.05 ; \beta=0.02, p>0.05$, respectively). Moreover, regulation of emotion revealed a significantly different path on negative comments $(Z=-2.12, p<0.05)$. This path coefficient was greater for losses $(\beta=-$ $0.25, p<0.01)$ than the coefficient for wins $(\beta=-0.06, p>0.05)$. Additionally, the relationship between adaptive coping and negative comments $(Z=-2.46, p<0.05)$ was 
significantly different between wins and losses. Also, this path was greater for losses $(\beta=-$ $0.28, p<0.01)$ than for wins $(\beta=-0.02, p>0.05)$. Thus, the results demonstrated the model's change in both groups, suggesting that the result of the game moderated the structural paths of the revised model.

\section{Discussion}

The overall purpose of this study was to examine the mediating effects of parents' coping strategies on the relationship between parents' EI and sideline verbal behaviors during their children's soccer games. In general, the hypothesized relationships were supported. Specifically, parents' regulation of emotion was positively related with praise/encouragement, and negatively with negative and derogatory comments (Hypothesis 1). As high levels of parents' emotion regulation are associated with sideline behaviors traditionally viewed as favorable for youth athletes (i.e., related with increase praise/encouragement; Teques, Serpa, Rosado, Silva, \& Calmeiro, 2018), high emotion regulation individuals are likely to exhibit fewer negative behaviors (i.e., criticism, insults and offensive behaviors). These results suggest that improvement of parents' emotion regulation may promote parents' desirable behaviors during their children's participation in competitive sport.

Consistent with previous studies in sport (Laborde et al., 2012), EI (regulation of emotion) was positively associated with adaptive coping, and negatively associated with maladaptive coping strategies (Hypothesis 2). Specifically, parents' emotion regulation was more strongly associated with reduced use of maladaptive coping strategies $\left(\beta=-0.32, R^{2}=\right.$ $.36)$, instead of increased use of adaptive coping $\left(\beta=0.19, R^{2}=.22\right)$. This result reinforces the argument that EI is likely to support rather than promote adaptive coping (Davis, 2013), and renews the discussion about the levels of conscientiousness on emotional regulation. Highlevel consciousness implies awareness of emotional reactions that includes extended selfreflection, whereas low-level consciousness involves a brief awareness that emerges in a 
superficial fashion and is unlikely to be recalled (Mayer \& Salovey, 1995). In this sense, parents may be aware that it is undesirable to express anger after the referee calls a penalty against their children's team, but they may not be fully aware of an adaptive strategy to cope with the situation. Future studies could examine the associations between parents' regulation of emotion and adaptive/maladaptive coping in more detail by analyzing moderating effects of intentional forms of emotional regulation, such as emotional attention (e.g., Gohm, 2003) or emotional self-efficacy (e.g., Kirk, Schutte, \& Hine, 2008).

Also, the present results expand current knowledge by demonstrating small to moderate mediating effects of coping strategies on the link between EI and individuals' behaviors (e.g., MacCann et al., 2011). As noted above, those who better regulate emotions engage more frequently in adaptive coping (e.g., active coping, humor) and are less likely to use maladaptive approaches such as denial or venting (e.g., Laborde et al., 2012). In turn, adaptive coping was positively related with praise/encouragement and negatively with negative comments (Hypothesis 3 and 4), whereas maladaptive coping was associated with negative and derogatory comments (Hypothesis 5 and 6). In other words, the mediating effects of coping strategies suggests that parents with high emotional regulation can manage emotions effectively and are thus more likely to select appropriate coping strategies to maintain optimal emotional balance and adopt appropriate behaviors.

The non-significant associations between regulation of emotion and both coping strategies with performance-feedback and instruction may imply that different behaviors are associated with varying degrees of emotional valence, including neutral emotional states (Barrett, 2006). Holt et al. (2008) placed parents' praise/encouragement, performancecontingent feedback, instruction, striking a balance, negative and derogatory comments on a continuum moving from more supportive to more controlling comments. Hence, performance-contingent feedback and instruction can be considered as neutral emotional 
valence behaviors that do not elicit emotional regulation or coping strategies. However, this interpretation is speculative, and future research should address how the hedonic tone of parents' emotional experiences (i.e., positive and negative emotions) and appraisal patterns are related with coping (see Lazarus, 1991).

In addition, the results regarding moderating effects of parents' gender show that the revised path model was invariant across mothers and fathers (Hypothesis 7). However, an analysis of the structural paths revealed that two paths coefficients for mothers (i.e., use of emotion $\rightarrow$ regulation of emotion, and regulation of emotion $\rightarrow$ praise/encouragement) were greater than the coefficients for fathers. Although the research on gender has contradictory results (e.g., Joseph \& Newman, 2010), the findings of the current study corroborate the idea that females may be better at regulating emotions than males (e.g., Farrelly \& Austin, 2007) resulting in the demonstration of more supportive behaviors. Nevertheless, more important than recognizing differences between genders, it is critical to analyze the possible interactions between gender and other variables (Fernández-Berrocal, Cabello, Castillo, \& Extremera, 2012). In this study, we analyzed gender moderating effects simultaneously with several variables, including EI subscales, coping strategies and behaviors. However, we did not systematically explore how different situations during the game may affect EI-coping processes. Given that EI-coping process is situational, it will be worthy for future studies to explore mothers' and fathers' EI, coping strategies and sideline verbal behaviors during different game situations (e.g., changes to game score, child in/out of game).

Another finding concerning moderating effects of game outcome on parents' behaviors is that the revised path model differs significantly between parents whose child's team is winning versus losing (Hypothesis 8). In general, results suggest that parents with high maladaptive coping use are more likely to provide more negative and derogatory comments when they watched a game that resulted in their children's defeat. On the contrary, parents 
with high regulation of emotion and adaptive coping are less likely to exhibit negative comments in a defeat. This finding supports the view that EI-coping processes may vary depending on the situation (Salovey et al., 1999), and to the best of our knowledge the present study is the first to address the effects of the situational conditions on the relationships between EI, coping strategies and behavior. These situational conditions may influence stress appraisals and subsequent emotional states (Lazarus, 2000). Therefore, it would be important to consider the actual emotions parents experience, because positive and negative emotions require different forms of processing information as well as different emotional regulation demands. It is likely that regulation of negative emotions is more taxing on cognitive resources than that of positive emotions. Negative emotions signal threat and are more distinguishable from a physiological and autonomic point of view compared to positive emotions (even among negative emotions). In addition, the appraisal processes that give rise to negative emotions are also more differentiated than those of positive emotions (Fredrickson, 2001). Therefore, negative emotions are more intense and may be more difficult for individuals to regulate. It might be that while winning, there is less need to self-regulate, but while losing, individuals have the need to interact with and change the environment triggered by an intense emotional experience.

Limitations and future research should be considered for the present study. Primarily, this study has a cross sectional design which precludes any causal interpretation of regression effects. Season long research that addresses processual effects over time would add to our understanding of how EI, coping, and parents' sideline verbal behaviors reciprocally impact each other. The classification of situational coping in adaptive and maladaptive coping strategies measured by the Brief COPE may not adequately reflect the coping conceptual structure. Future research should include short-form measures of coping that can capture other dimensions in which parents may cope with watching their child play. Likewise, researchers 
should consider that coping is a dynamic process and parents use multiple strategies simultaneously, both adaptive and maladaptive, to cope with stressors (e.g., during the course of a game, and in relation to sideline verbal behaviors) (Burgess et al., 2016). Also, evidence suggests that personality traits have the potential to influence how individuals manage emotions and cope with stressful events. For example, the Big Five Personality traits have been shown to predict specific, rather than broad, coping strategies (Connor-Smith \& Flachsbart, 2007). Likewise, students who hold pure personal standards perfectionism had higher levels of emotional intelligence, while those with pure evaluative concerns perfectionism scored lower on emotional intelligence (Gong, Fletcher \& Paulson, 2017). As studies in sport are still scarce, researchers should consider personality traits to understand the links between parents' emotional intelligence, coping strategies and sideline behaviors.

Moreover, persons change their emotional intelligence competencies with experience (Fernández-Berrocal, Gutiérrez-Cobo, Rodriguez-Corrales, \& Cabello, 2017); hence, future research should explore how parents' emotional intelligence competencies change as a function of repeated exposure to their children's competitive situations. As well, future studies should address the specific environmental constraints of the game (e.g., parents' interpersonal relationships, coaches' tactical decisions, game score variations, referee decisions) to examine their impact on the EI-coping processes. Finally, this study coded only the parents' verbal behaviors. It would be interesting for future studies to extend the analysis to nonverbal parents' behaviors.

In conclusion, the findings of this study offer several valuable contributions to the literature. First, from a conceptual perspective, the findings addressed a long-standing question about the hierarchical associations of EI components (i.e., emotion appraisals, use of emotion and emotion regulation), recognizing emotion regulation as the immediate determinant of individuals' adaptation (e.g., Joseph \& Newman, 2010; Salovey et al., 1999). 
Second, at an elementary descriptive level, the majority of sideline verbal behaviors were praise/encouragement, followed by performance-contingent feedback, instruction, and negative and derogatory comments. Hence, while negative parental sideline behaviors may be particularly concerning for coaches and administrators (e.g., Ross et al., 2015), the current study suggests that these behaviors are less frequent. Indeed, this interpretation is in line with evidence obtained from observational studies conducted in several countries, including Canada (Bowker et al., 2007; Holt et al., 2008), New Zealand (Kidman et al., 1999), the United States (Dorsch et al., 2014). Third, this study adds to the youth sport parenting literature by revealing some individual factors (i.e., regulation of emotion, adaptive and maladaptive coping strategies) that are associated with verbal sideline behaviors. Finally, the findings lend some support for Harwood and Knight's (2015) assertion that EI and adaptive coping are features of sport parenting expertise by revealing that regulation of emotion is related positively with desirable parents' sideline behaviors (i.e., praise/encouragement) and negatively with undesirable parents' sideline behaviors (i.e., negative comments, and derogatory comments). Overall, this study sheds light on the emotional experience of parents attending their children's games and suggests that EI and adaptive coping strategies may be useful approaches to include in sport parent educational initiatives in the future (cf. Knight \& Holt, 2013b; Ross et al., 2015). 


\section{References}

Bar-On, R. (2004). The Bar-On Emotional Quotient Inventory (EQ-i): Rationale, description and summary of psychometric properties. In G. Geher (Ed.), Measuring emotional intelligence: Common ground and controversy (pp. 115-145). Hauppauge, NY: Nova Science Publishers.

Barrett, L. F. (2006). Valence is a basic building block of emotional life. Journal of Research in Personality, 40, 35-55. doi: 10.1016/j.jrp.2005.08.006

Bowker, A., Boeknoven, B., Nolan, A., Bauhaus, S., Glover, P., Powell, T., et al. (2009). Naturalistic observations of spectator behavior at youth hockey games. The Sport Psychologist, 23, 301-316. doi: 10.1123/tsp.23.3.301

Carvalho, V. S., Guerrero, E., Chambel, M. J., \& González-Rico, P. (2016). Psychometric properties of WLEIS as a measure of emotional intelligence in the Portuguese and Spanish medical students. Evaluation and Program Planning, 58, 152-159. https://doi.org/10.1016/j.evalprogplan.2016.06.006

Carver, C. (1997). You want to measure coping but your protocol's too long: consider the brief COPE. International Journal of Behavioral Medicine, 4, 92-100. doi: 10.1207/s15327558ijbm0401_6

Cheung, G.W., \& Rensvold, R. B. (2002). Evaluating goodness-of-fit indices for testing measurement invariance. Structural Equation Modeling, 9, 233-255. doi: 10.1207/S15328007SEM0902_5

Cohen, J. (1988). Statistical Power Analysis for the Behavioral Sciences (2nd ed.). Hillsdale, NJ: Lawrence Earlbaum Associates.

Connor-Smith, J. K., \& Flachsbart, C. (2007). Relations between personality and coping: a meta-analysis. Journal of Personality and Social Psychology, 93, 1080-1107. doi: $10.1037 / 0022-3514.93 .6 .1080$ 
Davis, S. K. (2013). Can 'emotionally intelligent' coping promote adaptation in young people? Psychology of Education Review, 37, 5-12. https://eprints.worc.ac.uk/id/eprint/3042

Dorsch, T. E., Smith, A. L., Wilson, S. R., \& McDonough, M. H. (2014). Parent goals and verbal sideline behavior in organized youth sport. Sport, Exercise and Performance Psychology, 4, 19-35. doi: 10.1037/spy0000025

Dunn, E. W., Brackett, M. A., Ashton-James, C., Schneiderman, E., \& Salovey, P. (2007). On emotionally intelligent time travel: Individual differences in affective forecasting ability. Personality and Social Psychology Bulletin, 33, 85-83. doi: $10.1177 / 0146167206294201$

Farrelly, D., \& Austin, E. (2007). Ability EI as an intelligence? Associations of the MSCEIT with performance on emotion processing and social tasks and with cognitive ability. Cognition and Emotion, 21, 1043-1063. doi: 10.1080/02699930601069404

Faul, F., Erdfelder, E., Buchner, A., \& Lang, A.-G. (2009). Statistical power analyses using $\mathrm{G}^{*}$ Power 3.1: Tests for correlation and regression analyses. Behavior Research Methods, 41, 1149-1160. doi: 10.3758/BRM.41.4.1149

Fernández-Berrocal, P., Cabello, R., Castillo, R., \& Extremera, N. (2012). Gender differences in emotional intelligence: The mediating effect of age. Behavioral Psychology, 20, 7789.

Fernández-Berrocal, P., Gutiérrez-Cobo, M. J., Rodriguez-Corrales, J., \& Cabello, R. (2017). Teachers' affective well-being and teaching experience: The protective role of perceived emotional intelligence. Frontiers in Psychology, 8. doi: 10.3389/fpsyg.2017.02227

Fredrickson, B. L. (2001). The role of positive emotions in positive psychology: The broadenand-build theory of positive emotions. American psychologist, 56, 218-226. 
Gohm, C. L. (2003). Mood regulation and emotional intelligence: Individual differences. Journal of Personality and Social Psychology, 84, 594-607. doi: 10.1037/00223514.84.3.594

Goldstein, J. D., \& Iso-Ahola, S. E. (2008). Determinants of parents' sideline-rage emotions and behaviors at youth soccer games. Journal of Applied Social Psychology, 38, 14421462. doi: 10.1111/j.1559-1816.2008.00355.x

Gong, X., Fletcher, K. L., \& Paulson, S. E. (2017). Perfectionism and emotional intelligence: A test of the $2 \times 2$ model of perfectionism. Personality and Individual Differences, 106, 71-76. doi: 10.1016/j.paid.2016.10.015

Hair, J.F., Jr., Black, W.C., Babin, B.J., \& Anderson, R.E. (2014). Multivariate data analysis: A global perspective (7th ed.). Upper Saddle River, NJ: Pearson.

Harwood, C., \& Knight, C. (2009). Understanding parental stressors: an investigation of British tennis parents. Journal of Sports Sciences, 27, 339-351. doi: $10.1080 / 02640410802603871$

Harwood, C. G., \& Knight, C. J. (2015). Parenting in youth sport: A position paper on parenting expertise. Psychology of Sport and Exercise, 16, 24-35. doi: 10.1016/j.psychsport.2014.03.001

Holt, N. L., Tamminen, K. A., Black, D. E., Mandigo, J. L., \& Fox, K. R. (2009). Youth sport parenting styles and practices. Journal of Sport \& Exercise Psychology, 31, 37-59. doi: https://doi.org/10.1123/jsep.31.1.37

Holt, N. L., Tamminen, K. A., Black, D. E., Sehn, Z. L., \& Wall, M. P. (2008). Parental involvement in competitive youth sport settings. Psychology of Sport and Exercise, 9, 663-685. doi:10.1016/j.psychsport.2007.08.001 
597

598

599

600

601

602

603

604

605

606

607

608

609

610

611

612

613

614

615

616

617

618

619

620

621

Hu, L., \& Bentler, P. (1999). Cutoff criteria for fit indexes in covariance structure analysis: Conventional criteria versus new alternatives. Structural Equation Modeling, 6, 1-55. http://dx.doi.org/10.1080/10705519909540118

Joseph, D. L., \& Newman, D. A. (2010). Emotional intelligence: An integrative meta-analysis and cascading model. Journal of Applied Psychology, 95, 54-78. doi: 10.1037/a0017286

Kidman, L., McKenzie, A., \& McKenzie, B. (1999). The nature and target of parents' comments during youth sport competitions. Journal of Sport Behavior, 22, 54-68.

Kirk, B. A., Schutte, N. S., \& Hine, D. W. (2008). Development and preliminary validation of an emotional self-efficacy scale. Personality and Individual Differences, 45, 432-436. doi:10.1016/j.paid.2008.06.010

Kline, R. B. (2011). Principles and practice of structural equation modeling ( $3^{\text {rd }}$ ed.). The Guilford Press: New York.

Knight, C. J., \& Holt, N. L. (2013a). Factors that influence parents' experiences at junior tennis tournaments and suggestions for improvement. Sport, Exercise, and Performance Psychology, 2, 173-189. doi: 10.1037/a0031203

Knight, C. J., \& Holt, N. L. (2013b). Strategies used and assistance required to facilitate children's involvement in competitive tennis: parents' perspectives. The Sport Psychologist, 27, 281-291. doi: 10.1123/tsp.27.3.281

Laborde, S., Dosseville, F., \& Allen, M. S. (2016). Emotional intelligence in sport and exercise: A systematic review. Scandinavian Journal of Medicine \& Science in Sports, 26, 862-874. doi: $10.1111 / \mathrm{sms} .12510$

Laborde, S., Dosseville, F., Guillén, F., \& Chávez, E. (2014). Validity of the trait emotional intelligence questionnaire in sports and its links with performance satisfaction. Psychology of Sport and Exercise, 15, 481-490. http://dx.doi.org/10.1016/j.psychsport.2014.05.001 
622

623

624

625

626

627

628

629

630

631

632

633

634

635

636

637

638

639

640

641

642

643

644

645

646

Laborde S., You M., Dosseville F., \& Salinas A. (2012). Culture, individual differences, and situation: Influence on coping in French and Chinese table tennis players. European Journal of Sport Science, 12, 255-261. doi: 10.1080/17461391.2011.566367

Lazarus, R. S. (1991). Emotion and adaptation. New York, NY: Oxford University Press.

Lazarus, R. S. (2000). How emotions influence performance in competitive sports. The Sport Psychologist, 14, 229-252. https://doi.org/10.1123/tsp.14.3.229

Lee, Y. H., \& Chelladurai, P. (2016). Affectivity, emotional Labor, emotional exhaustion, and emotional intelligence in coaching. Journal of Applied Sport Psychology, 28, 170-184. doi: $10.1080 / 10413200.2015 .1092481$

Libbrecht, N., De Beuckelaer, A., Lievens, F., \& Rockstuhl, T. (2014). Measurement invariance of the Wong and Law emotional intelligence scale scores: Does the measurement structure hold across Far Eastern and European countries? Applied Psychology, 63, 223-237. doi: 10.1111/j.1464-0597.2012.00513.x.

MacCann, C., Fogarty, G. J., Zeidner, M., \& Roberts, R. D. (2011). Coping mediates the relationship between emotional intelligence (EI) and academic achievement. Contemporary Educational Psychology, 36, 60-70. doi:10.1016/j.cedpsych.2010.11.002

Marsh, H. W., Hau, K-T., \& Wen, Z. (2004). In search of golden rules: Comment on hypothesis-testing approaches to setting cutoff values for fit indexes and dangers of overgeneralizing Hu and Bentler's (1999) findings. Structural Equation Modeling, 11, 320-341. https://doi.org/10.1207/s15328007sem1103_2

Matud, M. P. (2004). Gender differences in stress and coping styles. Personality and Individual Differences, 37, 1401-1415. doi:10.1016/j.paid.2004.01.010

Mayer, J. D., \& Salovey, P. (1995). Emotional intelligence and the construction and regulation of feelings. Applied and Preventive Psychology, 4, 197-208. doi: 10.1016/S0962-1849(05)80058-7 
647

648

649

650

651

652

653

654

655

656

657

658

659

660

661

662

663

664

665

666

667

668

669

670

Mikolajczak, M. (2009). Going beyond the ability-trait debate: the three-level model of emotional intelligence. Electronic Journal of Applied Psychology, 5, 25-31.

McKenzie, T. L. \& van der Mars, H. (2015). Top 10 research questions related to assessing physical activity and its contexts using systematic observation. Research Quarterly for Exercise and Sport, 86, 13-29. doi: 10.1080/02701367.2015.991264

Nevitt, J., \& Hancock, G.R. (2001). Performance of bootstrapping approaches to model test statistics and parameter standard error estimation in structural equation modeling. Structural Equation Modeling, 8, 353-377. doi:10.1207/S15328007SEM0803_2

Omli, J., \& LaVoi, N. M. (2012). Emotional experiences of youth sport parents I: Anger. Journal of Applied Sport Psychology, 24, 10-25. doi: 10.1080/10413200.2011.578102

Petrides, K. V., Pita, R., \& Kokkinaki, F. (2007). The location of trait emotional intelligence in personality factor space. British Journal of Psychology, 98, 273-289. doi: $10.1348 / 000712606 \times 120618$

Ribeiro, J. L. P., \& Rodrigues, A. P. (2004). Questões acerca do coping: A propósito do estudo de adaptação do Brief COPE. [Some questions about coping: The study of the Portuguese adaptation of the Brief COPE]. Psicologia, Saúde \& Doenças, 5, 3-15.

Rodrigues, N., Rebelo, T., \& Coelho, J. V. (2011). Adaptação da Escala de Inteligência Emocional de Wong e Law (WLEIS) e análise da sua estrutura factorial e fiabilidade numa amostra portuguesa [Adaptation of the Wong and Law Emotional Intelligence Scale, factorial analysis and reliability of the Portuguese version]. Psychologica, 55, 189-207.

Ross, A. J., Mallett, C. J., \& Parkes, J. F. (2015). The influence of parent sport behaviours on children's development: Youth coach and administrator perspectives. International Journal of Sports Science and Coaching, 10, 605-621. doi: 10.1260/1747-9541.10.4.605 
Salovey, P., Bedell, B. T., Detweiler, J. B., \& Mayer, J. D. (1999). Coping intelligently: Emotional intelligence and the coping process. In C.R. Snyder (Ed.), Coping: The psychology of what works (pp. 141-164). New York: Oxford Press.

Salovey, P., \& Mayer, J. D. (1990). Emotional intelligence. Imagination, Cognition, and Personality, 9, 185-211. doi:0.2190/DUGG-P24E-52WK-6CDG

Schutte, N. S., Malouff, J. M., Hall, L. E., Haggerty, D. J., Cooper, J. T., Golden, C. J., \& Dornheim, L. (1998). Development and validation of a measure of emotional intelligence. Personality and Individual Differences, 25, 167-177. doi: 10.1016/S01918869(98)00001-4.

Tamminen, K. A., Poucher, Z. A., \& Povilaitis, V. (2017). The car ride home: An interpretive examination of parent-athlete sport conversations. Sport, Exercise, and Performance Psychology, 6, 325-339. doi: http://dx.doi.org/10.1037/spy0000093

Teques, P., Serpa, S., Rosado, A., Silva, C. \& Calmeiro, L. (2018). Parental involvement in sport: Psychometric development and empirical test of a theoretical model. Current Psychology, 37, 234-249. doi:10.1007/s12144-016-9507-2

Williams, J., \& MacKinnon, D. P. (2008). Resampling and distribution of product methods for testing indirect effects in complex models. Structural Equation Modeling, 15, 23-51. doi: $10.1080 / 10705510701758166$

Wong, C., \& Law, D. S. (2002). The effects of leader and follower emotional intelligence on performance and attitude: An exploratory study. Leadership Quarterly, 13, 243-274. doi: 10.1016/S1048-9843(02)00099-1 


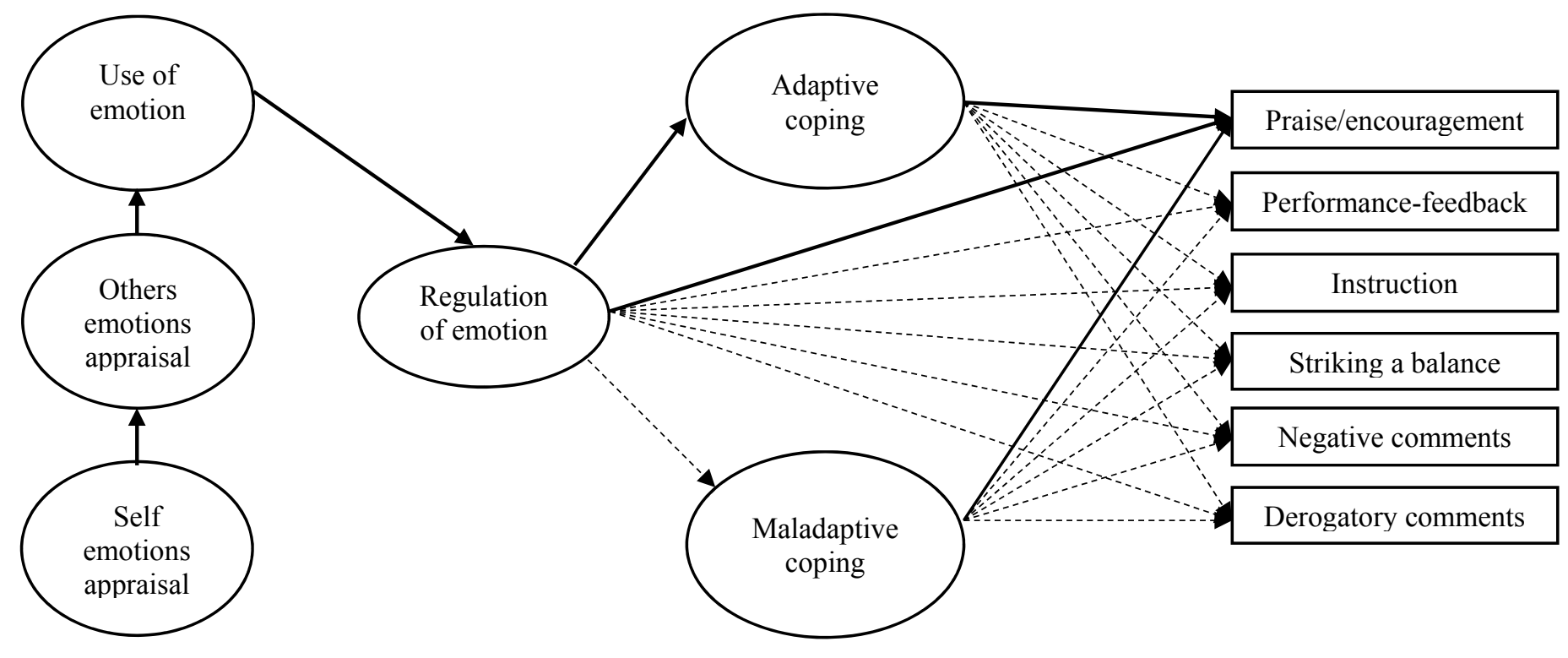

Figure 1. The hypothesized path model for the relationships between parents' emotional intelligence, coping strategies and sideline behaviors during their child's soccer games. Note. Positive paths in continuous lines; Negative paths in dashed lines. 


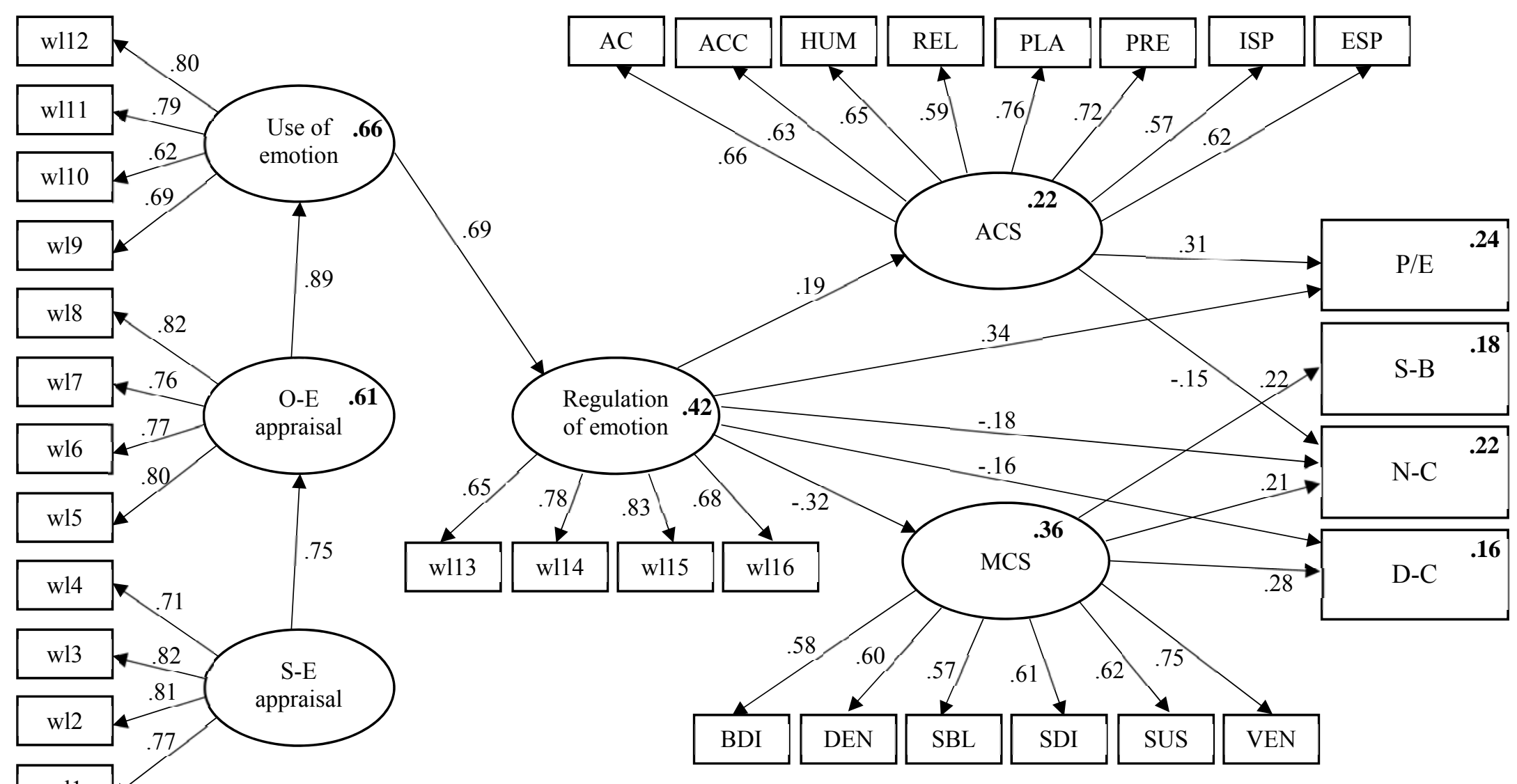

Figure 2. The revised path model. Note. All the standardized path coefficients are significant at the .05 level. In bold are the coefficients of determination $\left(\mathrm{R}^{2}\right)$. Non-significant paths were excluded for visual simplicity. $\mathrm{ACS}=$ adaptive coping, $\mathrm{AC}=$ active coping, $\mathrm{ACC}=$ acceptance, $\mathrm{HUM}=\mathrm{humor}, \mathrm{REL}=$ religion, $\mathrm{PLA}=$ planning, $\mathrm{PRE}=$ positive reframing, $\mathrm{ISP}=$ instrumental support, $\mathrm{ESP}=$ emotional support; $\mathrm{MCS}=$ maladaptive coping, $\mathrm{BDI}=$ behavioral disengagement, $\mathrm{DEN}=$ denial, $\mathrm{SBL}=$ self-blame, $\mathrm{SDI}=$ self-distraction, $\mathrm{SUS}=$ substance use, $\mathrm{VEN}=$ venting; $\mathrm{P} / \mathrm{E}=$ praise/encouragement, $\mathrm{S}-\mathrm{B}=$ striking a balance, $\mathrm{N}-\mathrm{C}=$ negative comments, $\mathrm{D}-\mathrm{C}=$ derogatory comments. 
Table 1

Descriptive statistics and bivariate correlations for all variables.

\begin{tabular}{|c|c|c|c|c|c|c|c|c|c|c|c|c|}
\hline & 1 & 2 & 3 & 4 & 5 & 6 & 7 & 8 & 9 & 10 & 11 & 12 \\
\hline 1. Self-emotions app & - & & & & & & & & & & & \\
\hline 2. Others-emotions app & $.64 * *$ & - & & & & & & & & & & \\
\hline 3. Use of emotion & $.63 * *$ & $.72 * *$ & - & & & & & & & & & \\
\hline 4. Regulation & $.38 * *$ & $.52 * *$ & $.71 * *$ & - & & & & & & & & \\
\hline 5. Adaptive coping & .04 & $.21^{*}$ & $.28 * *$ & $.17^{* *}$ & - & & & & & & & \\
\hline 6. Maladaptive coping & $-.35 * *$ & -.04 & $-.24 * *$ & $-.33 * *$ & $-.42 * *$ & - & & & & & & \\
\hline 7. Praise/encouragement & $.18^{* *}$ & $.16^{* *}$ & $.26 * *$ & $.28 * *$ & $.38 * *$ & $-.12 *$ & - & & & & & \\
\hline 8. Perform-feedback & $-.19 * *$ & $-.23 * *$ & $-.19 * *$ & $-.13 *$ & -.10 & .07 & $.36 * *$ & - & & & & \\
\hline 9. Instruction & $-.17 * *$ & $-.22 * *$ & $-.16 * *$ & $-.12 *$ & -.08 & .08 & $.31 * *$ & $.77 * *$ & - & & & \\
\hline 10. Striking balance & $-.22 * *$ & $-.28 * *$ & $-.13 *$ & $-.32 * *$ & -.06 & $.23 * *$ & $.21 * *$ & $.72 * *$ & $.75^{* *}$ & - & & \\
\hline 11. Negative comms & -.08 & $-.14^{*}$ & $-.13 *$ & $-.18 *$ & $-.16^{*}$ & $.18 * *$ & $.25 * *$ & $.55 * *$ & $.53 * *$ & $.57 * *$ & - & \\
\hline 12. Derogatory comms & -.04 & -.06 & $-.11 *$ & $-.17 *$ & $-.11 *$ & $.21 * *$ & .12 & $.39 * *$ & $.39 * *$ & $.23 * *$ & $.47 * *$ & - \\
\hline Mean & 3.96 & 3.81 & 3.88 & 3.65 & 2.66 & 2.22 & 16.60 & 12.23 & 13.55 & 5.67 & 2.56 & 1.65 \\
\hline Standard deviation & 0.69 & 0.71 & 0.65 & 0.67 & 0.52 & 0.50 & 6.30 & 5.16 & 7.89 & 1.89 & 1.12 & 1.03 \\
\hline Range & $2.25-5.00$ & $1.50-5.00$ & $2.50-5.00$ & $1.00-5.00$ & $1.25-3.81$ & $1.00-3.58$ & $2-32$ & $0-23$ & $0-36$ & $0-12$ & $0-5$ & $0-4$ \\
\hline
\end{tabular}

Note. ${ }^{*} p<.05, * * p<.01$ 
Table 2

Standardized indirect effects and confidence intervals

\begin{tabular}{|c|c|c|c|}
\hline \multirow[t]{3}{*}{ Mediating paths } & \multirow[t]{3}{*}{ Estimate } & \multirow{2}{*}{\multicolumn{2}{|c|}{$95 \% \mathrm{CI}$}} \\
\hline & & & \\
\hline & & Lower & Upper \\
\hline Emotion regulation $\rightarrow$ Adaptive coping $\rightarrow$ Praise/encouragement & .18 & .10 & .29 \\
\hline Emotion regulation $\rightarrow$ Adaptive coping $\rightarrow$ Negative comms & -.09 & -.21 & -.02 \\
\hline Emotion regulation $\rightarrow$ Maladaptive coping $\rightarrow$ Negative comms & -.12 & -.25 & -.02 \\
\hline Emotion regulation $\rightarrow$ Maladaptive coping $\rightarrow$ Derogatory comms & -.08 & -.19 & -.01 \\
\hline
\end{tabular}




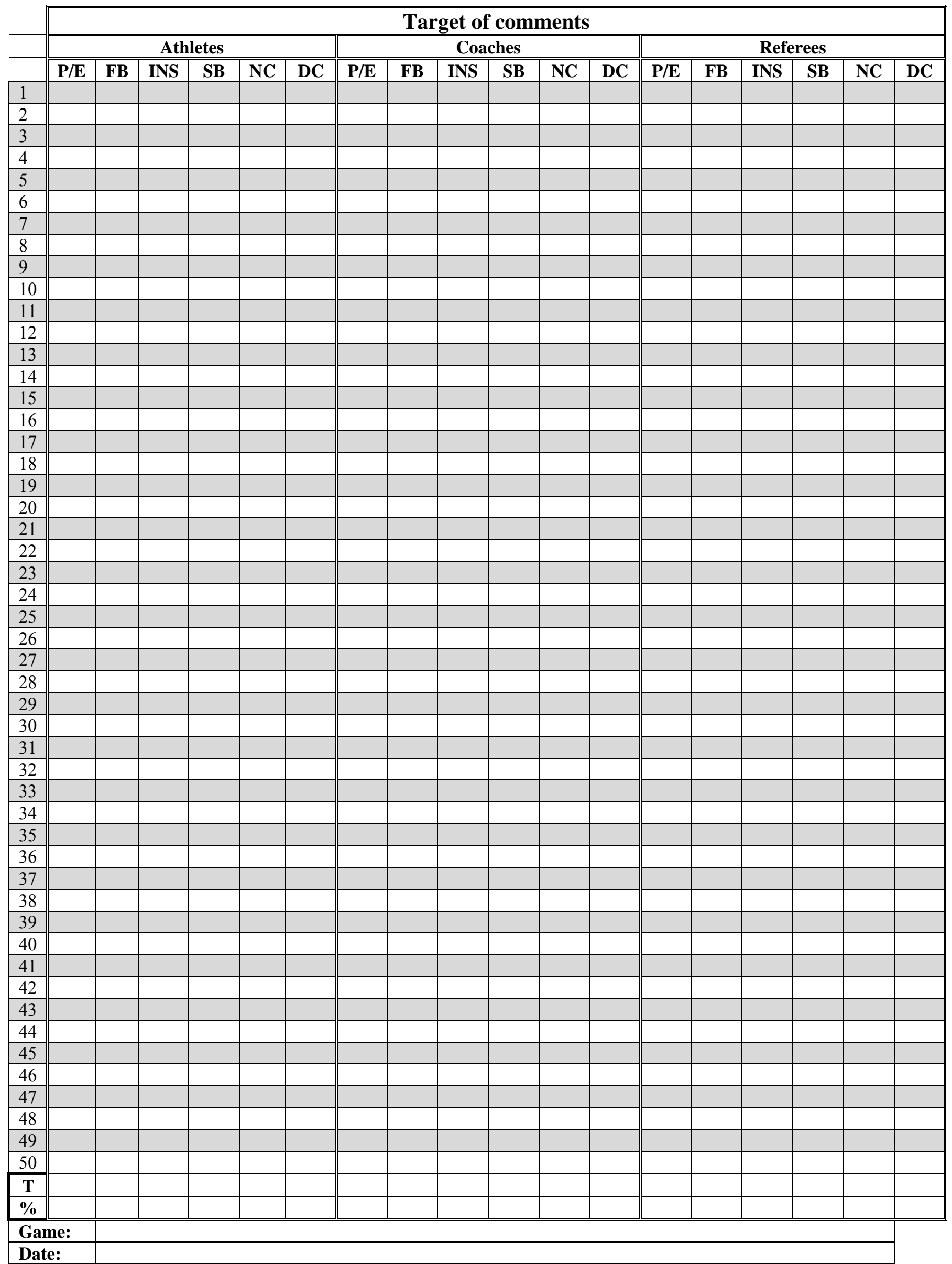

Date:

Note. $\mathrm{P} / \mathrm{E}=$ praise/encouragement, $\mathrm{FB}=$ Performance Feedback; INS = Instruction; $\mathrm{SB}=$ striking a balance, $\mathrm{NC}=$ negative comments, $\mathrm{DC}=$ derogatory comments. 